\title{
Origin of the Mesozoic Boreal realm
}

SIR - Environmental factors that brought the Mesozoic Borial realm into being have been discussed in the Geological Magazine by R. E. H. Reid (1973) and A. Hallam (1973). I wish to add to this discussion by presenting two curves of faunal resemblance (Figs 1,2) which help to define the time of existence of the realm. The curves relate only to ammonite faunas, but the debate on Boreal-Tethyan faunal relationships during the Mesozoic has concerned these organisms more than any others.

One of the curves compares the total ammonite assemblage of the Boreal Ocean with that of the Tethys through time. The other makes a similar comparison between ammonites of the western and eastern Tethys. In the latter comparison the western Tethys includes the Mediterranean basin, the Crimea, and Sinai; the eastern Tethys extends from the Middle East to Indonesia. Each curve has been developed from a sequence of indices of resemblance between ammonite faunas of the sea areas concerned, drawing upon data from Arkell, Kummel \& Wright (1957) with considerable supplementation from other sources especially for the Triassic. Each index of faunal resemblance expresses as a percentage the result of dividing the number of ammonite genera known to be common to the two areas under comparison by the total number of ammonite genera in the smaller of the 2 assemblages. The indices for each stage are shown as isolated points on the diagrams. The curves themselves have been plotted by calculating a mean index for each group of 3 stages, thus broadening the foundation for each point at the cost of some generalization of the result. Gaps in data have been bridged by simple averaging: where this has been done there is no isolated point on the illustrations to represent the simple, unmodified index. The first and last members of a series have been modified for graphing by weighting them by one-third with the simple index of the adjoining stage. Late Cretaceous data from the Boreal region is weak and so a broken line is employed in Figure 1 for this span of time.

The graphs present a quantified although generalized statement of well-known longterm trends in ammonite provincialism. Short-term fluctuations such as the Late Oxfordian temporary reversal of the Late Jurassic Boreal spread (Arkell, 1956, p. 612) are not expressed. Figure 1 indicates that the most marked and most persistent differentiation into Boreal and Tethyan assemblages of Mesozoic ammonites occurred from about Callovian to Aptian time. It also shows that the degree of resemblance at genus level between the high and low latitude ammonite assemblages varies almost from zero to $100 \%$ during the Mesozoic. By contrast, Figure 2 comparing faunas of 2 sea regions both in low to middle latitudes indicates that a fairly steady although possible declining relationship existed throughout the Jurassic and Cretaceous between these 2 areas. Such difference as did exist has been recognized by authors who have defined separate Mediterranean and Himalayan provinces within the Mesozoic Tethyan realm. The apparent downward trend of the curve may be related to a gradual loss of definition of the Tethys Ocean during later Mesozoic geographical changes including the opening of the North Atlantic Ocean.

The persistent high degree of resemblance between the two lower latitude assemblages of Figure 2 contrasts with the fluctuating resemblance between a high and a low latitude assemblage shown in Figure 1. This supports the long and widely held view that ammonite distributions were strongly influenced by a factor related to latitude generally considered to be water temperature. The Boreal-Tethys curve suggests further that whatever the factor may be its effects have varied strikingly through time. Biologically significant factors most obviously related to latitude are light and temperature including seasonal effects, and secondary consequences derived from these. Marine salinity level has a relationship to latitude but there is a general acceptance that salinity is not the fundamental cause of the development and maintenance of the Boreal realm. Because of the evident essential constancy of illumination from the sun, factors related to light are probably not the most important cause of the fluctuating level of faunal differentiation between the Boreal and Tethyan Oceans. The global temperature regime on the other hand has varied greatly through geological time. The influence of temperature may

Geol. Mag. 112 (2), 1975, pp. 199-201. Printed in Great Britain. 
be enhanced through seasonal change and, as Reid (1973) has pointed out, seasonality may operate not necessarily on the ammonites themselves but on the marine food chain at a fundamental level.

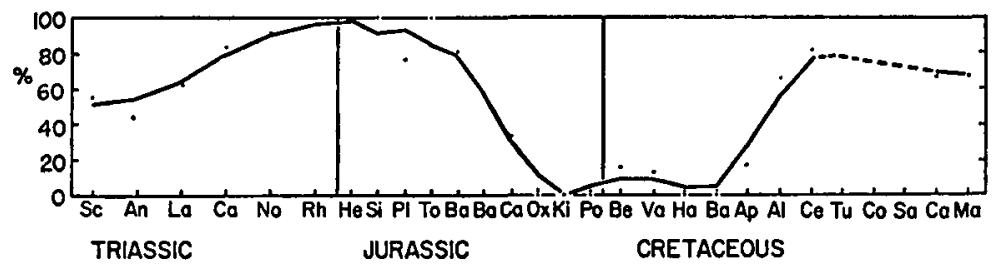

Figure 1. Resemblance at genus level of Boreal ammonite assemblages to those of the Tethys Ocean. Mesozoic stage names are abbreviated to the first 2 letters.

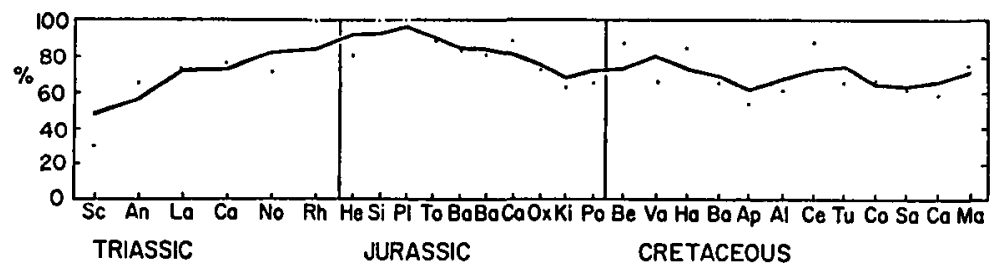

Figure 2. Resemblance at genus level of western Tethys ammonite assemblages to those of the eastern Tethys.

Assessment of Boreal-Tethys faunal relationships in their time context supports the contention that temperature influences in some form were the most important control on broader patterns of Mesozoic ammonite distribution. Several authors in the recent symposium volume on the boreal Lower Cretaceous (Casey \& Rawson, 1973) have stressed the biogeographic significance of temperature. Among them, I refer particularly to Viera Scheibnerová who had already described anti-boreal or austral faunal assemblages in previous work (Scheibnerová, 1971). The recognition of even weakly developed austral assemblages strengthens the argument in favour of temperature control. At the ecological level of analysis many factors additional to temperature exert critical influence on marine communities, but the leading role of temperature on global distribution of ammonites seems to be well established. It follows that the Boreal-Tethys curve of ammonite faunal resemblance is an expression of biologically significant long-term variation in the Mesozoic climatic regime. The coincidence of the beginning and the ending of the Mesozoic Boreal Realm with, respectively, episodes of widespread, marine regression and transgression is notable. It suggests that the assumed fuctuation in temperature regime could have been related to alterations of oceanic circulation brought about by the geographical changes.

The rising trend in the Triassic segment of both curves is part of a general tendency towards uniformity perceptible among marine invertebrate faunas and land floras and faunas at this time (Gordon, 1973). I interpret this broad trend as a probable indication that climatic differentiation between low and high altitude was weakening throughout the Triassic. However, the continued existence of a temperature differential between lower and higher latitudes strong enough to have biological significance even in the Late Triassic is possibly shown by the low and middle latitude distribution of the newly developing reef corals at that time. Figure 1 suggests that the Late Triassic relative homogeneity of ammonite faunas continued over into the Early Jurassic in spite of the great changeover of world ammonite faunas. It appears, then, that the temperature regime remained similar too, at first, but that as the Jurassic progressed there was a 
steepening of the latitudinal temperature gradient which ultimately brought into existence separate Boreal and Tethyan ammonite realms.

\section{References}

Arkell, W. J., 1956. Jurassic Geology of the World. Oliver \& Boyd Ltd., Edinburgh \& London.

Arkell, W. J., Kummel, B. \& Wright, C. W., 1957. Mesozoic Ammonoidea. In: Moore, R. C. (Ed.): Treatise on Invertebrate Paleontology, part L (Mollusca 4), p. L80-L437. Geol. Soc. Amer. and Univ. Kansas Press.

Casey, R. \& Rawson, P. F. 1973. The Boreal Lower Cretaceous. Geological Journal Special Issue 5. Seel House Press, Liverpool.

Gordon, W. A, 1973. Changing geography of Triassic life. Geol. Soc. Amer. Abstracts with Programs, 5, 642.

Hallam, A. 1973. Origin of the Mesozoic 'Boreal' realm. Geol. Mag. 110, 69-70.

Reid, R. E. H. 1973. Origin of the Mesozoic 'Boreal' realm. Geol. Mag. 110, 67-9.

Scheibnerová. V. 1971. Foraminifera and their Mesozoic biogeoprovinces. Records Geol. Survey New South Wales 13 (part 3), 135-74.

Department of Geological Sciences

W. ANTHONY GORDON

University of Regina

Regina, Saskatchewan

Canada, S4S OA2

13th September, 1974.

\section{Classification of the Mediterranean Quaternary}

SIR - I would like to draw attention to some problems of stratigraphical classification presented by the marine Quaternary deposits of the Mediterranean.

They are now commonly divided into six Stages, named, from oldest to youngest, Calabrian, Emilian, Sicilian, Milazzian, Tyrrhenian, Versilian. The first to be defined were the Sicilian (1872), Calabrian (1910) and Tyrrhenian (1914), the definition of each being based on the presence of various molluscan species which had immigrated from the Atlantic. Subsequently the Milazzian (1918), Versilian (1942) and Emilian (1949) Stages were proposed to accommodate deposits laid down during intervals when immigrant faunas were, or were thought to be, altogether absent.

Of the immigrant faunas themselves, none is ubiquitous throughout the Mediterranean region. In recognition of this, Gignoux (1913) concluded that classification must be based not only upon faunas but also upon sea-levels and 'sedimentary cycles'. Such criteria were accordingly included in the original definitions of the Milazzian and Versilian Stages, and have also been included in new definitions proposed from time to time for the other four (Hey, in press). This has led to serious ambiguity, for the relationship between faunal and eustatic changes in the Quaternary Mediterranean is a matter on which there has been much speculation but, as yet, little agreement.

Any further discussion of the classification of these deposits should, of course, take place within the context of the recommendations recently issued by the International Subcommission on Stratigraphic Classification. For the definition of chronostratigraphic units, these require the designation of boundary-stratotypes 'chosen in sequences of essentially continuous deposition at or near markers which are as favorable as possible for long-distance chronocorrelation' (ISSC, 1972, 312). For the base of the Calabrian Stage a boundary-stratotype at Le Castella, Calabria, was proposed in 1965 at the Seventh INQUA Congress, the boundary itself to be defined, as in the original definition of Gignoux (1910), by the arrival of the first cool-temperate Atlantic immigrants. No stratotype, however, has yet been designated for any boundary within the Quaternary.

Geol. Mag. 112 (2), 1975, pp. 201-202. Printed in Great Britain. 